\title{
MECHANICS OF THE TAPERED INTERFERENCE FIT IN DENTAL IMPLANTS
}

\author{
Dinçer Bozkaya and Sinan Müftü* \\ Department of Mechanical Engineering \\ Northeastern University \\ 334 Snell Engineering Center \\ Boston, MA 02115
}

Submitted to Journal of Biomechanics as an Original Article

October 2002

\begin{abstract}
In evaluation of the long-term success of a dental implant, the reliability and the stability of the implant-abutment interface plays a great role. Tapered interference fits provide a reliable connection method between the abutment and the implant. In this work, the mechanics of the tapered interference fits was analyzed using a closed-form formula and the finite element (FE) method. An analytical solution, which is used to predict the contact pressure in a straight interference, was modified to predict the contact pressure in the tapered implant-abutment interface. An elastic-plastic finite element model was used to simulate the material non-linearity of the implant and abutment material. The validity and the applicability of the analytical solution were investigated by comparisons with the FE model for a range of problem parameters. It was shown that the analytical solution could be used to determine the pull-out force and loosening-torque with 5-10\% accuracy. Detailed analysis of the stress distribution due to tapered interference fit, in a commercially available, abutment-implant system was carried out. This analysis shows that plastic deformation in the implant limits the increase in the pull-out force that would have been otherwise predicted by higher interference values.

Keywords: Dental implants; Taper lock; Morse taper; Conical interference fit; Tapered interference fit; Connection mechanism; Pull-out force; Loosening torque
\end{abstract}

* Corresponding author. E-mail: smuftu@ coe.neu.edu, Phone/Fax: +(617) 373-4743/2921 


\section{INTRODUCTION}

Dental implant-abutment systems are used as anchors to support single or multiunit prostheses for partially or fully edentulous patients. A dental implant system consists of an implant that is surgically implanted in maxilla or mandible, and an abutment that mates with the implant once the implant successfully osseointegrates to the bone. Depending on the specific system used, an abutment can include a machined or welded connection mechanism within itself or can be clamped onto the implant by means of an abutment screw. The dental prosthesis is then fabricated over the abutment. In general, the success of the treatment depends on many factors affecting the bone-implant, implant-abutment and abutment-prosthesis interfaces (Geng et al., 2001). In this paper we analyze the mechanics of the tapered interference fit used in some implant-abutment systems.

Two types of connection methods involving a) a screw, and b) a tapered interference fit (also called Morse taper) are commonly used for securing the abutment to the implant. Fig. 1 shows various implant systems: designs by Astra (Astra Tech AB, Mölndal, Sweden) and Nobel Biocare (Nobel Biocare AB, Göteborg, Sweden) use a screw; designs by Ankylos (Degussa Dental, Hanau-Wolfgang, Germany) and ITI (Institut Straumann AG, Waldenburg, Switzerland) use a screw with tapered end; and the design by Bicon (Bicon Inc., Boston, MA, USA) uses solely a tapered interference fit. For the systems using a screw, the connection between the implant and the abutment depends on the screw-preload, which is generated by applying a predetermined amount of torque during installation. Designs in which the screw has a large tapered end essentially work like a tapered interference fit, and the screw threads do not appear to contribute to the connection (Schwartz et al., 2000; Binon et al., 1994; Sutter et al., 1993). The tapered interference fit relies on the large contact pressure and resulting frictional resistance, in the mating region of the implant-abutment interface, to provide a secure connection.

In screw type implant-abutment connection mechanism, mechanical complications such as screw loosening when occlusal loads exceed the preload, or creep deformation in the screw-implant interface can lead to clinical complications (Schwartz et al., 2000). When the tapered-interference fits are used, the abutment loosening seems to be less of a problem (Müftü and Chapman 1997; Morgan and Chapman 1999; Keating, 
2001; Sutter et al. 1993). The free body diagram of the abutment in Fig. 2 shows that resultant axial force due to biting is $F_{b}=\left(N+N_{b}\right)(\mu \cos \theta-\sin \theta)$, where $\mu$ is the static friction coefficient, $N$ is the resultant contact force due to initial interference, $N_{b}$ is the additional normal force due to biting and $\theta$ is the taper angle. The biting force acts in the direction of the abutment insertion, hence aids to secure the connection. This situation is in direct contrast to implants using screws where the biting force lowers the pretension in the screw. The mechanism for the tapered interference fit to become loose, is the application of a loosening torque $T_{L}$ or a pull-out force $F_{p}$.

Brunski (1999) indicated tensile axial loading could develop in implants supporting multi-unit splinted implant restorations and cantilevered prostheses. Therefore a sufficiently large amount of pull-out force is necessary for the long-term stability of a dental implant-abutment system using the tapered interference fit. Later in this paper, formulas are developed for $T_{L}$ and $F_{p}$.

In general, interference fits provide a connection method between a hub and a shaft without using a third member such as a key, pin, bolt, or screw. The connection allows load transmission due to the friction forces between the mating surfaces where the shaft has a slightly larger diameter than the hub. The tapered interference fits are used commonly in engineering practice such as Morse tapers, used to engage lathe bits (Sutter et al., 1993). In the medical applications tapered interference fits are used in total hip prosthesis in addition to dental implants (Chu et al. 1999). Mechanics of a cylindrical interference fit is well understood, and can be found in design text books (e.g., Shigley and Mischke, 1989). The elastic-plastic behavior of the cylindrical interference fits has also been analyzed (Gammer and Müftui, 1990). No known analytical solution to the tapered interference fit problem exists to the best of our knowledge. FE method has been used to investigate the mechanics of tapered interference fits in hip implants (e.g.,Van Rietbergen et al., 1993; Viceconti et al., 2000; Chu et al., 2000).

The dependent characteristics of the interference fit, such as the pull-out and insertion forces and the stress distribution in the members, depend on the taper angle, contact length, inner and outer diameters of the members, depth of insertion, material properties and coefficient of friction. In this paper the mechanics of a general tapered interference fit is analyzed. A closed form formula is derived to predict the contact 
pressure between the tapered members, based on plane stress elasticity. The analytical solution is used to determine the interrelations between the parameters. The finite element method is used to verify the validity of the formula. A detailed analysis of the interference fit in a Bicon implant is presented including the analytical, purely elastic and elastic-plastic FE analyses.

\section{MATERIALS AND METHODS}

\section{Geometrical considerations}

A schematic description of a generic tapered interference fit of two cylinders, embedded in a cylindrical bone, is shown in Fig. 3a. The middle cylinder (implant) has an outer radius $b_{2}$ and has a tapered hole in the center with top and bottom radii $r_{i t}$ and $r_{i b}$, respectively. The depth of the hole is $L_{h}$ and the total height of the cylinder is $L_{h}+L_{s}$. The inner-most part is a truncated cone representing the abutment, with top and bottom radii of $r_{a t}$ and $r_{a b}$, respectively. The length of the abutment is $L_{a}$. The taper angle $\theta$ is the same for both pieces. A cylindrical coordinate axis is located on the top of the implant as shown in the figure.

When the abutment is placed in the implant with no interference, the bottom of the abutment will be located at $z=z^{*}=\left(r_{i t}-r_{a b}\right) / \tan \theta$. Application of an external axial force in $+z$-direction will cause the abutment to engage with the implant with an interference fit. An axial displacement by an amount $\Delta z$ measured with respect to $z=z^{*}$, will cause an interference $\delta=\Delta z \tan \theta$ in the radial direction, as shown in the Fig. 3a. The total length of the contacting interface of the abutment and the implant then becomes $L_{c}=\left(r_{i t}-r_{a b}\right) / \sin \theta+\Delta z / \cos \theta$.

\section{Analytical Model}

The geometry of the tapered interference fit is deceptively simple; but, no known analytical treatment of this problem exists to the best of our knowledge. In order to develop a relation for the contact pressure in a tapered interference fit, first we revisit the formula for calculating the interference conditions of two straight cylinders, depicted in Fig. 3b. The plain stress solution to a cylinder subjected to an inner pressure $P_{i}$ and an 
outer pressure $P_{o}$, as shown in Fig. 3c, is well known (Shigley and Mischke, 1989). The radial displacement $u(r)$ of such a cylinder is,

$$
u(r)=\frac{1}{E}\left[-\frac{a^{2} b^{2}\left(P_{o}-P_{i}\right)}{\left(b^{2}-a^{2}\right) r}(1+v)+\frac{P_{i} a^{2}-P_{o} b^{2}}{\left(b^{2}-a^{2}\right)}(1-v) r\right] \quad a \leq r \leq b .
$$

Consider two cylinders whose radii have an initial interference $d$ as shown in Fig. $3 \mathrm{~b}$. The inner cylinder has an outer radius $b_{1}$ and, the outer cylinder has inner and outer radii of $a_{2}$ and $b_{2}$, respectively. The initial interference is, then, $\delta=b_{1}-a_{2}$. Once the cylinders are engaged, the total radial displacement of the interface will be equal to the initial interference, $\delta=u_{1}\left(b_{1}\right)-u_{2}\left(a_{2}\right)$. This is the geometric constraint of the interference. When the interference takes place we get $P_{o 1}=P_{i 2}=P_{c}$ (see Fig. 3c). The interference depth $d$ is small when compared to the radii of the cylinders, therefore it can be assumed that interference occurs at the radius $r=a_{2}=b_{1}$. The contact pressure $P_{c}$ due to interference is calculated by combining equation (1) with the geometric constraint as follows (Shigley and Mischke, 1989),

$$
P_{c}=\frac{E \delta\left(b_{2}^{2}-b_{1}^{2}\right)}{2 b_{1} b_{2}^{2}}
$$

Note that equation (2) is valid if the material properties of the mating cylinders are the same, i.e., $E_{1}=E_{2}=E$ and $v_{1}=v_{2}=v$.

Brichi et al. (2001) analyzed the mechanics of a tapered interference fit by approximating the smooth tapered walls by a series of straight cylinders with changing radii and diminishing height. By applying the plain stress formula, given in equation (1), to each cylinder, the contact pressure distribution of the whole conical interface can be approximated. Fig. 3a shows that the outer radius of the abutment $b_{1}(z)$ and the inner radius of the implant $a_{2}(z)$ vary linearly along the axis $z$ as follows,

$$
\begin{array}{ll}
b_{1}(z)=r_{a b}+\left(L_{c} \cos \theta-z\right) \tan \theta & \text { for } 0 \leq z \leq z^{*}+\Delta z \\
a_{2}(z)=r_{i t}-z \tan \theta & \text { for } 0 \leq z \leq L_{h}
\end{array}
$$

Then, using equations (2) and (3), the contact pressure due to interference of a tapered interference fit, as a function of the axial distance becomes, 


$$
P_{c}(z)=\frac{E \delta\left[b_{2}^{2}-b_{1}^{2}(z)\right] \cos \theta}{2 b_{1}(z) b_{2}^{2}} .
$$

The accuracy of this equation is checked, by comparing the results with the FE analysis.

\section{The effect of the bone on the contact pressure in the implant-abutment interface}

In practice, the implant and the abutment are surrounded by the bone. In this section, expressions for the contact pressure in the abutment-implant (a-i) and implantbone (i-b) interfaces are developed. In the implant-abutment-bone system, the interface between the implant and the abutment, at $r=r_{2}\left(=b_{1}(z)\right)$, has an initial interference $\delta$, and the interface between the implant and the bone, at $r=r_{3}\left(=b_{2}\right)$, has zero interference. These conditions are expressed as;

$$
\begin{aligned}
& \delta=u_{1}\left(r_{2}\right)-u_{2}\left(r_{2}\right) \text { at } r=r_{2}, \\
& 0=u_{2}\left(r_{3}\right)-u_{3}\left(r_{3}\right) \text { at } r=r_{3} .
\end{aligned}
$$

By using similar assumptions as given above, the formulas for contact pressure in the

implant-abutment interface $P_{c}^{(a-i)}$ and in the abutment-bone interface $P_{c}^{(i-b)}$ are found from simultaneous solution of equations (1), (5) and (6) as follows,

$$
\begin{aligned}
P_{c}^{(a-i)} & =\frac{E \delta \cos \theta}{2} \frac{E\left[b_{3}^{2}\left(1+v_{b}\right)+b_{2}^{2}\left(1-v_{b}\right)\right]\left(b_{2}^{2}-b_{1}^{2}(z)\right)+E_{b}\left[b_{1}^{2}(z)(1+v)+b_{2}^{2}(1-v)\right]\left(b_{3}^{2}-b_{2}^{2}\right)}{b_{1}(z) b_{2}^{2}\left\{E\left[b_{3}^{2}\left(1+v_{b}\right)+b_{2}^{2}\left(1-v_{b}\right)\right]+E_{b}(1-v)\left(b_{3}^{2}-b_{2}^{2}\right)\right\}} \\
P_{c}^{(i-b)} & =\frac{E E_{b} \delta b_{1}(z)\left(b_{3}^{2}-b_{2}^{2}\right)}{b_{2}^{2}\left\{E\left[b_{3}^{2}\left(1+v_{b}\right)+b_{2}^{2}\left(1-v_{b}\right)\right]+E_{b}(1-v)\left(b_{3}^{2}-b_{2}^{2}\right)\right\}}
\end{aligned}
$$

Note that in these equations as the elastic modulus of the bone approaches zero, $P_{c}^{(a-i)}$ approaches the expression given in equation (4) and that $P_{c}^{(i-b)}$ approaches zero.

\section{Pull-out Force and Torque}

The resultant contact force $N$ due to the interference fit is obtained by the integration of the contact pressure $P_{c}$ over the contact area along the tapered interface, 


$$
N=2 \pi \int_{0}^{L_{c} \cos \theta} b_{1}(z) P_{c}(z) d z
$$

A free body diagram of the assembly would show that the pull-out force $F_{p}$ is equal to,

$$
F_{p}=N(\sin \theta-\mu \cos \theta) .
$$

Thus a closed form for solution for the approximate pull-out force of a tapered interference fit is obtained by using equations (4), (9) and (10) as follows,

$$
F_{p}=\frac{\pi E \delta L_{c}}{3 b_{2}^{2}}\left[3\left(b_{2}^{2}-r_{a b}^{2}\right)-L_{c} \sin \theta\left[3 r_{a b}+L_{c} \sin \theta\right]\right](\sin \theta-\mu \cos \theta) \cos ^{2} \theta .
$$

This equation shows that the pull-out force increases linearly with $\delta$ and $E$; and it increases as $\left(L_{c}\right)^{3}$. This result points the importance of a large contact surface in the abutment-implant interface. The formula also shows that if the taper angle is chosen such that $\tan \theta=\mu$, then the pull out force will be equal to zero. Fig. 4 shows the pull outforce $F_{p}$, for different implant radius $b_{2}$, contact length $L_{c}$, and taper angle $\theta$ values, typical for dental implants. Figures $4 \mathrm{a}, 4 \mathrm{c}$ and $4 \mathrm{~d}$ show that increasing contact length causes an increase of the pull-out force. Similarly, Figures $4 \mathrm{a}, 4 \mathrm{~b}$ and $4 \mathrm{c}$ show that increasing the implant radius $b_{2}$ causes the pull out force to increase. Finally, Fig. $4 \mathrm{~b}$ and $4 \mathrm{~d}$ show that the pull-out force is higher for smaller taper angles. Close inspection of these figures show that, predicted pull-out force $F_{p}$ values are relatively large. For example, from Fig. 4c, the pull out force is predicted to be, $F_{p}=1700 \mathrm{~N}$, for $b_{2}=1.5 \mathrm{~mm}$, $\theta=3^{\circ}, L_{c}=2 \mathrm{~mm}$. This value is considerably larger than the tensile load of $200 \mathrm{~N}$, that can be encountered in one of the implants supporting a full-denture as predicted by Brunski (1999).

The external torque value, which causes the abutment to become loose is given by,

$$
\begin{aligned}
T_{L} & =2 \pi \mu \int_{0}^{L_{c} \cos \theta} b_{1}^{2}(z) P_{c}(z) d z \\
& =\frac{\pi \mu E \delta L_{c} \cos ^{2} \theta}{4 b_{2}^{2}}\left\{L_{c} \sin \theta\left[2\left(b_{2}^{2}-3 r_{a b}^{2}\right)-L_{c} \sin \theta\left(4 r_{a b}+L_{c} \sin \theta\right)\right]+4 r_{a b}\left(b_{2}^{2}-r_{a b}^{2}\right)\right\}^{.}
\end{aligned}
$$


This equation shows that the loosening-torque increases with $\left(L_{c}\right)^{4}$. The trends of dependence of $T_{L}$ on $b_{2}, L_{c}$, and $\theta$ are similar to that of the $F_{p}$.

\section{Interference fit analysis using the FE method}

The finite element method was used, here, to analyze the mechanics of the tapered interference fit. First, the predictions of the interference fit formula given by equation (4) were compared to the results of the FE analysis. In this analysis, the material was assumed to behave elastically. Second, the mechanics of the interference fit in a Bicon implant-abutment system shown in Table 2, embedded in a cylinder to represent the bone, was analyzed. In the second analysis, the implant and the abutment were modeled with bilinear elastic-plastic material properties and large deformation elasticity option.

Ansys ver. 5.7 (Ansys Inc., Houston, Pennsylvania, USA) was used in the analyses. The CAD drawings were created in Pro/Engineer 2000i (PTC, Needham, MA, USA). First, the implant and the abutment were assembled without any interference. Then, in order to obtain different interference values, the abutment was displaced different $\Delta z$ amounts in the axial direction, relative to the implant. This creates overlapping of the contact boundaries. The assemblies with overlapping boundaries were, then, imported into Ansys. The abutment-implant system was modeled using axisymmetric Plane 42 elements. The tapered contact interfaces were simulated by Target 179 and Contact 172 elements. The implant was constrained in all degrees of freedom at the bottom face. The contact algorithm of the FE analysis code, then, finds the equilibrium-state, where the overlap is eliminated.

\section{RESULTS AND CONCLUSIONS}

\section{Comparison of tapered interference formula to FE analysis}

$\mathrm{FE}$ analysis was used to check the validity of equation (4). The length of the solid part of the implant $L_{s}$ was kept large, in order to minimize the effect of the fixed boundary. All materials were assumed to be linear and isotropic with $E=200 \mathrm{GPa}$, ? = 0.3 . Three different $L_{c} \cos ? / b_{1}$ values $(4,6,12)$ and three different $b_{2} / b_{1}$ values $(3,4,5)$ were used for each one of the three taper angles $\theta=3^{\circ}, 6^{\circ}$ and $9^{\circ}$. 
Fig. 5 shows the comparison of the contact pressure distribution predicted by equation (4) and the FE analysis, for $\theta=9^{\circ}, L_{c} \cos ? / b_{1}=4, b_{2} / b_{1}=5$, and $\delta / b_{1}=4 \times 10^{-4}$. The insert on Fig. 5 shows the FE mesh and the contact pressure distribution at the abutment-implant interface. Fig. 5 shows that the FE analysis predicts stress concentrations at the ends of the contact interface. The FE analysis and closed-form results, in general agree well; the contact pressure increases toward the tip $(z=160 \mathrm{~mm})$ where the implant is thicker, thus provide more resistance to deformation. However, it is clear that the closed-form approach, which is based on the plane-stress theory, does not capture the stress concentrations, particularly near the tip where $z \rightarrow z^{*}+\Delta z$.

Similar observations are made for the $P_{c}$-vs- $z$ comparisons of the other parameter combinations. The two approaches are compared conveniently, when the pull-out force $F_{p}$ and loosening torque $T_{L}$ values are evaluated for both the $\mathrm{FE}$ analysis and the closed form solution. Table 1 shows the $F_{p}$ and $T_{L}$ for different $\theta, L_{c} \cos ? / b_{1}, b_{2} / b_{1}$ and $\delta / b_{1}$ values. Here we see that the closed-form formula given by equation (11) underestimates the FE results between $5.46 \%-9.26 \%$. Considering the assumptions involved in the derivation of equation (4), this is a reasonable level of agreement.

\section{The effect of the bone on the contact pressure in the implant-abutment interface}

Equation (7) gives the contact pressure distribution $P_{c}^{(a-i)}$ in the abutment-implant interface, with the effect of the surrounding bone. This equation shows that three parameters related to the bone, its elastic modulus $E_{b}$, Poisson's ratio $v_{b}$ and outer radius $b_{3}$ affect the $P_{c}^{(a-i)}$ distribution. Figures $6 \mathrm{a}$ and $6 \mathrm{~b}$ show the effect of $E_{b}$ and $b_{3}$, respectively. Here it can be seen that a 16 -fold increase in $E_{b}$ causes nearly $10 \%$ increase in the contact pressure. The relation of the contact pressure to the outer radius of the bone is non-linear, as shown in Fig. 6b, where the contact pressure changes about $3.3 \%$ between $b_{3}=1 \mathrm{~mm}$ and $6 \mathrm{~mm}$, but no appreciable change occurs for thicker bone. These

results show that, the bone does not affect the contact pressure distribution in the abutment-implant interface more than $10 \%$. 


\section{The FE analysis for Bicon implant-abutment system}

The contact pressure and internal stress distribution in a Bicon implant-abutment system were analyzed using the FE method. Different interference values were obtained by assembling the implant and the abutment with $\Delta z=0.05,0.1,0.15,0.2$ and $0.25 \mathrm{~mm}$ in the vertical direction as described above. The bone was approximated by a $15.24 \mathrm{~mm}$ long cylinder with $11.68 \mathrm{~mm}$ in diameter, leaving $4.2 \mathrm{~mm}$ of bone around the implant, which is sufficient to eliminate the boundary effects in mesial-distal direction (Teixera et al. 1998).

All the materials were assumed to be isotropic. Bone was assumed to be linear, homogenous with $E_{b}=10 \mathrm{GPa}, ? b=0.3$. Full osseointegration was assumed and was modeled by fixing the implant to the bone. Implant and abutment material were Ti6Al4V ELI. A bilinear, isotropic hardening model was used in order to simulate the plasticity of Ti6Al4V ELI. The material properties of this material are: elastic modulus $E=113.8$ GPa; tangent modulus $E_{t}=0.63 \mathrm{GPa}$; yield stress $\sigma_{\mathrm{Y}}=960 \mathrm{MPa}$, ultimate strain $\varepsilon_{\mathrm{U}}=$ 0.08 ; Poisson's ratio $?=0.34$. The geometric non-linearity was also taken into account by using the large displacement option in the FE analysis. The results of the FE analysis are presented using the equivalent von Mises stresse and strain.

Figures 7a-e give the von-Mises stress distributions for $\Delta z=0.05-0.25 \mathrm{~mm}$, and Fig. $7 \mathrm{f}$ shows the equivalent strain for $\Delta z=0.25$. Note that the effect of the bone is considered in the analysis but not shown in these figures. The maximum von Mises stress for $\Delta z=0.05 \mathrm{~mm}$, which occurs near the bottom of the contact interface, is $692 \mathrm{MPa}$; the abutment and the implant both deform elastically. The stresses in the implant are higher than the abutment, as the latter is a stiffer due to its solid geometry. Plastic deformation starts at $0.1 \mathrm{~mm}$ insertion depth in the implant, near the top and the bottom of the contact area. This is consistent with the stress concentrations mentioned in the previous section. The rest of the implant and the abutment are elastically deformed. For $\Delta z$ values greater than $0.1 \mathrm{~mm}$, the plastic deformation spreads to the other regions of implant. A small region of plastic deformation in the abutment can be seen at $\Delta z=0.15 \mathrm{~mm}$, which spreads deeper into the abutment at higher $\Delta z$ values. Even at the highest level of abutment insertion considered here, the outer periphery of the implant remains elastic. The 
equivalent stress distribution at this level is shown in Fig. 7e for $\Delta z=0.25 \mathrm{~mm}$. The equivalent strain distribution for the same $\Delta z$ value is shown in Fig. 7f, which shows that except for the tip of the implant the strain level is less than 0.03. The largest equivalent strain occurs also at the tip of the implant and it is greater than the ultimate strain for this material 0.08 .

The contact pressure distribution $P_{c}^{(a-i)}$ at the abutment-implant interface of the Bicon system, evaluated by the FE method, were compared to the results of equation (7). The outside of the Bicon implant has fins as shown in Fig. 1. The results presented in Fig. 8 , were calculated for the inner, $\left(b_{2}=1.14\right)$ and outer radii, $\left(b_{2}=1.75\right)$ of the fins, separately. An equivalent implant radius $\left(b_{2}=1.51\right)$ was taken to be the radii of the cylinder with a height of contact length that has the same cross-sectional area as the implant area along the contact length.

Fig. 8 shows stress concentrations at the lower and upper intersection of the implant and abutment. The analytical solution cannot predict the pressure values in these regions. The analytical and FE results are close in the central $90 \%$ of the contact length. Since the implant radius is maximum at the bottom of the interface, the finite element results were well approximated by the upper curve using the largest implant radii, whereas at the top of the interface, the contact pressure was approximated better by the lower curve, using the smallest implant radius.

The pull-out force $F_{p}$ and the loosening torque $T_{L}$ calculated using an equivalent implant radii for this implant-abutment system as a function of insertion depth $\Delta z$, with different approaches are shown in Fig. 9. The closed-form formula, given by equation (7), predicts the pull-out force with $8-9 \%$ error by using the mean radius. If the material is treated as perfectly elastic, then the $F_{p}$ and $T_{L}$ values increase linearly as a function of insertion depth. When the plastic deformation of the material is considered, the pull-out force and the loosening torque increase non-linearly, and tend to level off. This result indicates that increasing insertion depth does not necessarily correspond to unbounded increase in pull-out force or loosening torque values.

\section{Acknowledgements}


The authors would like to acknowledge the support of Bicon Dental Implants, Boston, MA for this work, and the technical help of Dr. Ali Müftü at Tufts University, School of Dental Medicine. 


\section{References}

- Becker, W., Becker, B. E., 1995. Replacement of Maxillary and Mandibular Molars With Single Endosseous Implant Restorations: A Retrospective Study. J. Prosthet. Dent. 74, 51-55.

- Binon, P., Sutter, F., Beaty, K., Brunski, J., Gulbransen, H., Weiner, R., 1994. The Role of Screws in Implant Systems. Int. J. Oral Maxillofac. Implants 9, 49-63.

- Brunski, J. B., 1999. In Vivo Bone Response to Biomechanical Loading at the Bone/Dental-Implant Interface. Adv. Dent. Res. 13, 99-119.

- Chu, Y.-H., Alias, J.J., Duda, G.N., Frassica, F.J., Chao, E.Y.S., 2000. Stress and micromotion in the taper lock joint of a modular segmental bone replacement prosthesis. Journal of Biomechanics., 33, 1175-1179.

- Gamer, U., Müftü, S., 1990. On the Elastic-Plastic Shrink Fit with Supercritical Interference. ZAMM 70(11), 501-507.

- Geng, J., Tan, K. B. C., Liu, G., 2001. Application of Finite Element Analysis in Implant Dentistry: A Review of the Literature. The Journal of Prosthetic Dentistry 85, 585-598.

- Jemt, T., 1991. Failures and Complications in 391 Consecutively Inserted Fixed Prostheses Supported by Branemark Implants in Edentulous Jaws: A Study of Treatment From the Time of Prosthesis Placement to the First Annual Checkup. Int. J. Oral Maxillofac. Implants 6, 270-276

- Kallus, T., Bessing, C., 1994. Loose Gold Screws Frequently Occur in Full-Arch Fixed Prostheses Supported by Osseointegrated Implant After 5 Years. Int. J. Oral Maxillofac. Implants 9, 169-178.

- Keating, K., 2001. Connecting Abutments to Dental Implants 'An Engineer's Perspective.' Irish Dentist.

- Levine, R. A., Clem, D. S., Wilson, T. G., Higginbottom, F., Saunders, S. L., 1997. A Multicenter Retrospective Analysis of the ITI Implant System Used for Single-Tooth Replacements: Preliminary Results at 6 or More Months of Loading. Int. J. Oral Maxillofac. Implants 12, 237-242.

- Morgan, K. M., Chapman, R. J., 1999. Retrospective Analysis of an Implant System. Compendium of Continuing Education in Dentistry 20(7), 609-614. 
- Müftü, A., Chapman, R. J., 1998. Replacing posterior teeth with freestanding implants: four-year prosthodontic results of a prospective study. Journal of the American Dental Association 129(8), 1097-1102.

- O'Callaghan, J., Jr., Goddard, T., Birichi, R., Jagodnik, J. and Westbrook, S., 2001. Abutment Hammering Tool for Dental Implants. American Society of Mechanical Engineers, IMECE-2002 Proceedings Vol. 2, Nov. 11-16, 2002, Paper No. DE25112.

- Schwarz, M. S., 2000. Mechanical Complications of Dental Implants. Clin. Oral Impl. Res. 11, 156-158.

- Shigley, J. E., Mischke, C. R., 1989. Mechanical Engineering Design. McGraw-Hill, Singapore.

- Siegel, M. J., Maleev, V. L., Hartman, J. B., 1965. Mechanical Design of Machines. International Textbook Company, Pennsylvania.

- Sutter, F., Weber, H. P., Sorensen, J., Belser, U., 1993. The New Restorative Concept of the ITI Dental Implant system: Design and Engineering. Int. J. Periodont. Rest. Dent. 13, 409-431.

- Teixeria, E. R., Sato, Y., Akawaga, Y., Shindoi, N., 1998. A Comparative Evaluation of Mandibular Finite Element Models With Different Lengths and Elements For Implant Biomechanics. Journal of Oral Rehabilitation 25, 299-303.

- Van Rietbergen, B., Huiskes, R., Weinans, H., Sumner, D.R., Turner, T.R., and Galante, J.O., 1993. The mechanism of bone remodeling and resorption around pressfitted THA systems. Journal of Biomechanics. 26(4/5), 369-382.

- Viceconti, M., Muccini R., Bernakiewicz, M., Massimiliano, B., and Cristofolini, L., 2000. Large sliding contact elements accurately predict levels of bone-implant micromotion relevant to osseointegration. Journal of Biomechanics. 33, 1611-1618.

- Zarb, G. A., Schmitt, A., 1990. The Longitudinal Clinical Effectiveness of Osseointegrated Dental Implants: The Toronto Study. Part III: Problems and Complications Encountered. J. Prosthetic Dentistry. 64, 185-194. 


\section{NOMENCLATURE}

$a$ : inner radii of the cylinder

$b$ : outer radii of the cylinder

$a_{l}$ : inner radii of the abutment

$b_{1}$ : outer radii of the abutment

$a_{2}$ : inner radii of the implant

$b_{2}$ : outer radii of the implant

$a_{3}$ : inner radii of the bone

$b_{3}$ : outer radii of the bone

$r_{a t}$ : top radii of the abutment

$r_{a b}$ : bottom radii of the abutment

$r_{i t}$ : inner top radii of inner cylinder

$r_{i b}$ : inner bottom radii of inner cylinder

$L_{h}$ : depth of hole

$L_{s}$ : length of implant under the hole

$L_{a}$ : length of abutment

$L_{c}$ : contact length

$E$ : Young's modulus

$E_{t}$ : Tangent modulus

$E_{b}$ : Young's modulus of the bone

$e_{e q}:$ equivalent von Mises strain

$e_{u}:$ ultimate strain

?: Poisson's ratio

$?_{b}$ : Poisson's ratio of the bone

$r$ : radial location

$u$ : radial displacement

$z$ : position of abutment

$z^{*}:$ position of the abutment with no interference

$? z$ : insertion depth

$d$ : interference depth 
?: taper angle

$\mu$ : coefficient of friction

$P_{c}$ : contact pressure

$P_{i}$ : pressure applied to the inner surface of the cylinder

$P_{o}$ :pressure applied to the outer surface of the cylinder

$P_{c}^{(a-i)}$ : Contact pressure in abutment-implant interface

$P_{c}^{(i-b)}$ : Contact pressure in implant-bone interface

$s_{Y}$ : yield stress

$s_{e q}$ : equivalent von Mises stress

$N$ : total normal force acting on the contact area due to the contact pressure

$N_{b}$ : total normal force acting on the contact area due to biting forces

$F_{p}:$ pull-out force

$F_{b}$ : resultant axial force due to biting

$T_{L}$ : loosening torque 


\begin{tabular}{|c|c|c|c|c|c|c|c|c|c|}
\hline & \multicolumn{9}{|c|}{$\boldsymbol{b}_{2} / \boldsymbol{b}_{1}\left(\right.$ for $\left.d / b_{l}=4 \times 10^{-4}, L_{c} \cos \theta / b_{l}=4\right)$} \\
\hline & \multicolumn{3}{|c|}{3} & \multicolumn{3}{|c|}{4} & \multicolumn{3}{|c|}{5} \\
\hline$\theta$ & FEA & Eqn. (4) & $\%$ Error & FEA & Eqn. (4) & $\%$ Error & FEA & Eqn. (4) & $\%$ Error \\
\hline $\mathbf{3}^{\mathbf{0}}$ & $673 \mathrm{kN}$ & $620 \mathrm{kN}$ & -7.88 & $717 \mathrm{kN}$ & $663 \mathrm{kN}$ & -7.53 & $733 \mathrm{kN}$ & $683 \mathrm{kN}$ & -6.82 \\
\hline $6^{0}$ & 572 & 525 & -8.22 & 610 & 570 & -6.56 & 632 & 591 & -6.49 \\
\hline \multirow[t]{3}{*}{$9^{0}$} & 463 & 431 & -6.91 & 509 & 477 & -6.29 & 528 & 498 & -5.68 \\
\hline & \multicolumn{9}{|c|}{$\boldsymbol{L}_{c} \cos \theta / \boldsymbol{b}_{1}\left(\right.$ for $\left.d / b_{1}=4 \times 10^{-4}, b_{2} / b_{1}=3\right)$} \\
\hline & \multicolumn{3}{|c|}{4} & \multicolumn{3}{|c|}{6} & \multicolumn{3}{|c|}{12} \\
\hline$\theta$ & FEA & Eqn. (4) & $\%$ Error & FEA & Eqn. (4) & $\%$ Error & FEA & Eqn. (4) & $\%$ Error \\
\hline $3^{\mathbf{0}}$ & $673 \mathrm{kN}$ & $620 \mathrm{kN}$ & -7.88 & $991 \mathrm{kN}$ & $916 \mathrm{kN}$ & -7.57 & $1851 \mathrm{kN}$ & $1733 \mathrm{kN}$ & -6.37 \\
\hline $6^{0}$ & 572 & 525 & -8.22 & 817 & 758 & -7.22 & 1396 & 1300 & -6.88 \\
\hline \multirow[t]{3}{*}{$9^{\circ}$} & 463 & 431 & -6.91 & 647 & 603 & -6.80 & 1464 & 1384 & -5.46 \\
\hline & \multicolumn{9}{|c|}{$\boldsymbol{d} / \boldsymbol{b}_{1}\left(\right.$ for $\left.b_{2} / b_{1}=3, L_{c} \cos \theta / b_{1}=4\right)$} \\
\hline & \multicolumn{3}{|c|}{$1 \times 10^{-4}$} & \multicolumn{3}{|c|}{$4 \times 10^{-4}$} & \multicolumn{3}{|c|}{$8 \times 10^{-4}$} \\
\hline$\theta$ & FEA & Eqn. (4) & $\%$ Error & FEA & Eqn. (4) & $\%$ Error & FEA & Eqn. (4) & $\%$ Error \\
\hline $3^{0}$ & $168 \mathrm{kN}$ & $155 \mathrm{kN}$ & -7.74 & $673 \mathrm{kN}$ & $620 \mathrm{kN}$ & -7.88 & $1353 \mathrm{kN}$ & $1240 \mathrm{kN}$ & -8.35 \\
\hline $6^{0}$ & 142 & 131 & -7.75 & 572 & 525 & -8.22 & 114 & 105 & -7.89 \\
\hline $9^{\circ}$ & 116 & 108 & -6.90 & 463 & 431 & -6.91 & 950 & 862 & -9.26 \\
\hline
\end{tabular}

Table 1. Comparison of the pull-out force $F_{p}$ calculated by the closed form solution given by Eqn. (11) and the results of the FEA, for a tapered interference fit by using $b_{1}=40 \mathrm{~mm}, E=200 \mathrm{GPa}, ?=0.3$.

\begin{tabular}{|l|l|l|l|l|}
\hline BICON & Size & Part Number & Length & Material \\
\hline Implant & $3.5 \mathrm{~mm}$ & $260-740-211$ & $11.12 \mathrm{~mm}$ & Ti6Al-4V ELI \\
\hline Abutment & $4 \times 6.5 \mathrm{~mm} 0^{\circ}$ & $260-140-002$ & N/A & Ti6Al-4V ELI \\
\hline
\end{tabular}

Table 2. The Bicon implant-abutment system used in the FEA of the interference fit 


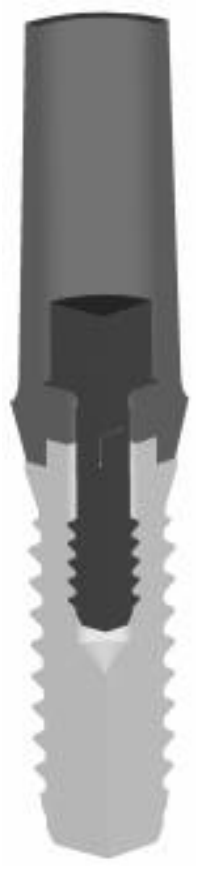

Nobel Biocare

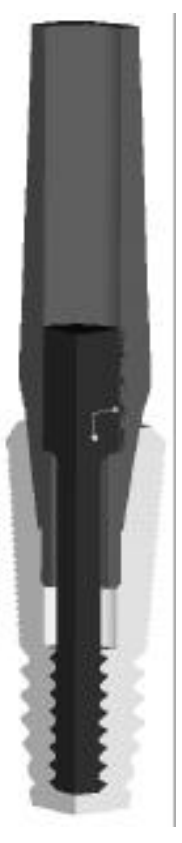

Astra

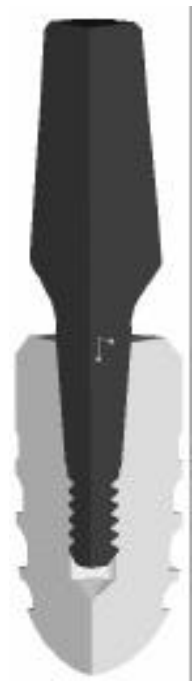

Ankylos

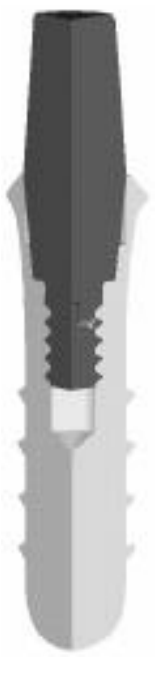

ITI

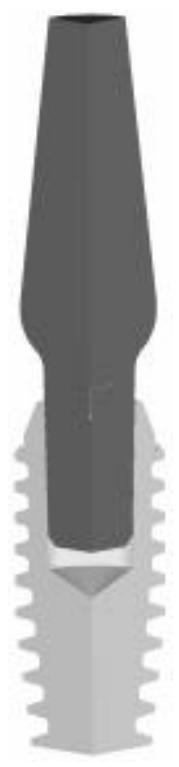

Bicon

Fig. 1. Different implant-abutment attachment methods. Astra and Nobel Biocare use a screw, Ankylos and ITI use a screw with an interference fit and Bicon uses onlyinterference fit. 


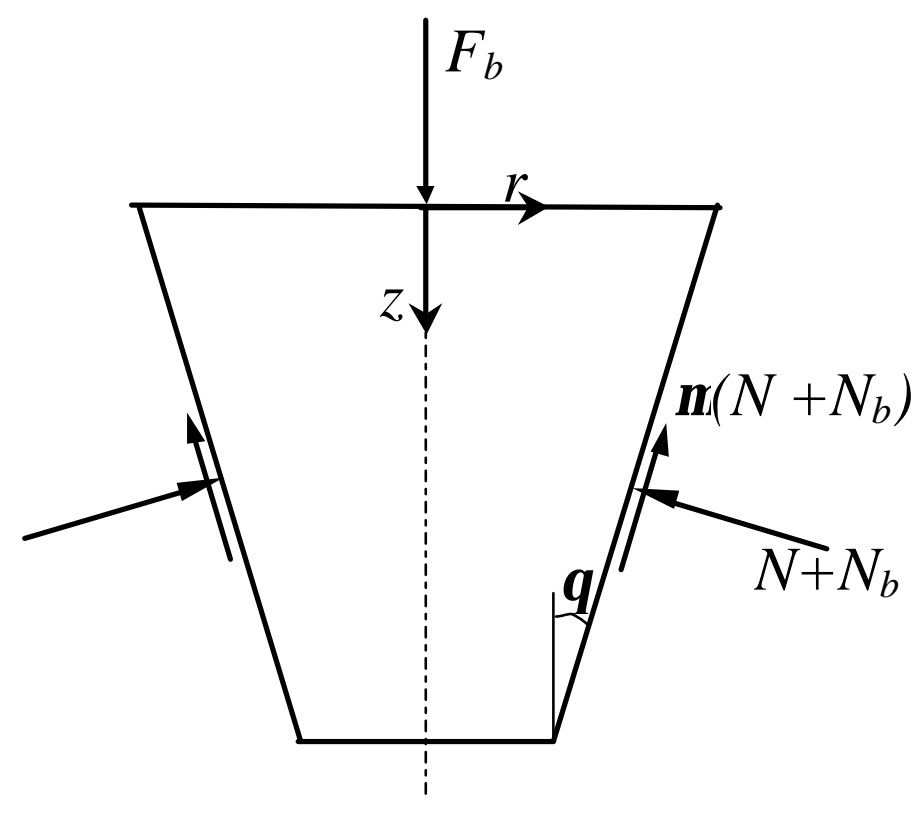

Fig. 2. Equilibrium of the forces acting on the abutment when an axial biting force $F_{b}$ is applied. A normal force due to initial insertion $N$, a normal force due to biting $N_{b}$, and a tangential force of magnitude $\mu\left(N+N_{b}\right)$ act on the tapered wall. Note that $N$ and $N_{b}$ are the resultants of the axisymmetric reaction forces. 


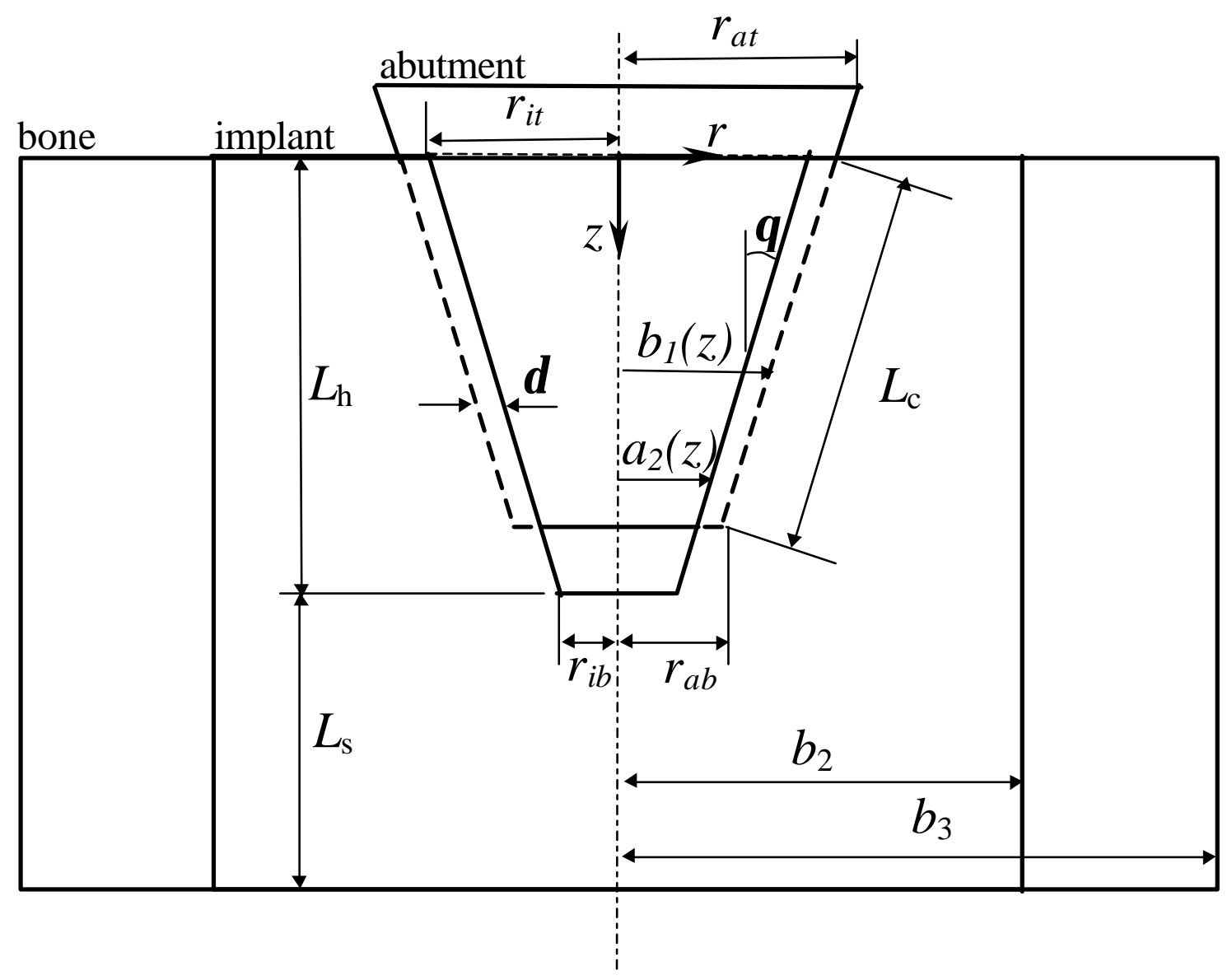

a)

Fig. 3. a) The geometry of a tapered interference fit composed of an outer bone, inner implant and a tapered abutment. b) The geometry of a regular interference fit of a solid shaft with an outer diameter of $b_{2}$ and a hollow shaft of outside diameter $b_{1}$ and inside diameter $a_{1}$. c) A hollow shaft subjected to inner pressure $p_{i}$ and outer pressure $p_{o}$. The initial interference between the parts in both a) and b) is $\delta$. 


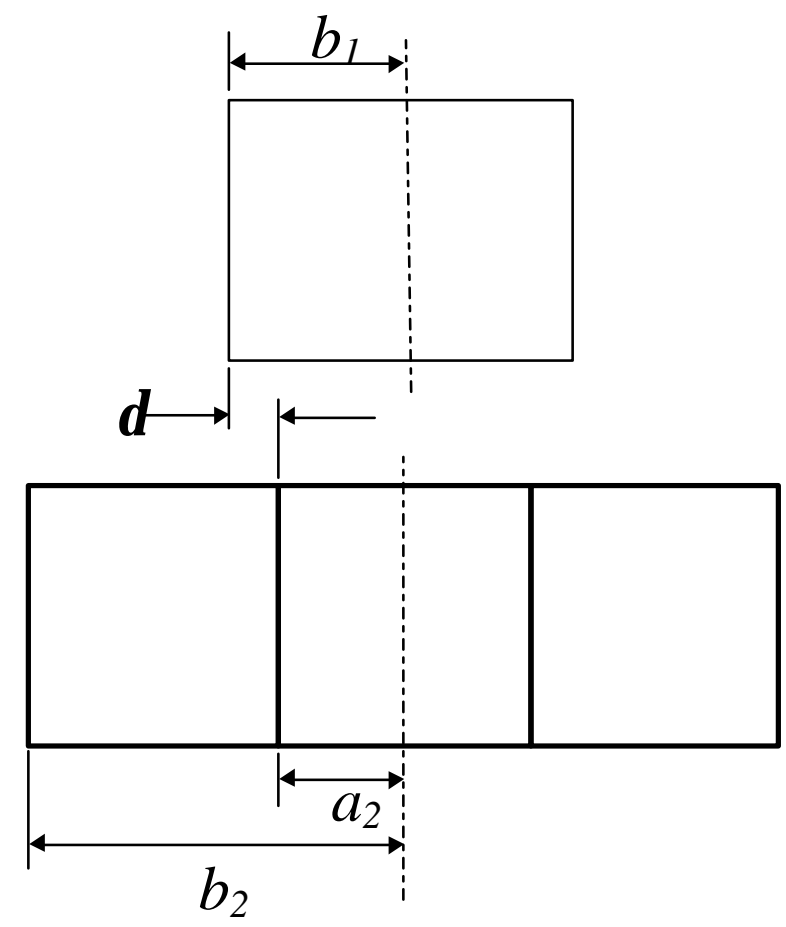

b)

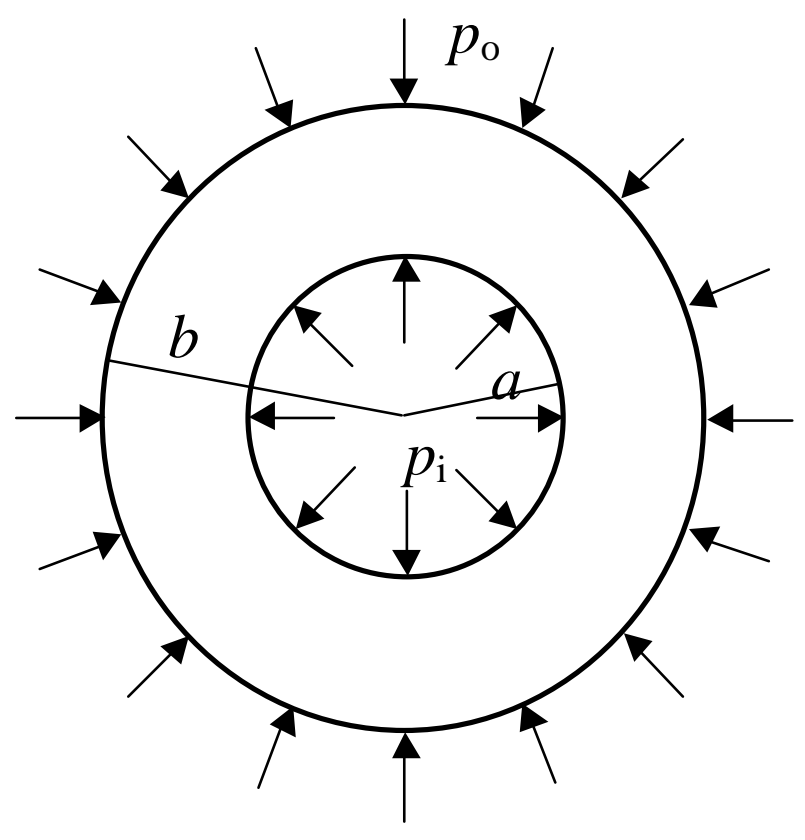

c)

Fig. 3. a) The geometry of a tapered interference fit composed of an outer bone, inner implant and a tapered abutment. b) The geometry of a regular interference fit of a solid shaft with an outer diameter of $b_{2}$ and a hollow shaft of outside diameter $b_{1}$ and inside diameter $a_{1}$. c) A hollow shaft subjected to inner pressure $p_{i}$ and outer pressure $p_{o}$. The initial interference between the parts in both a) and b) is $\delta$. 


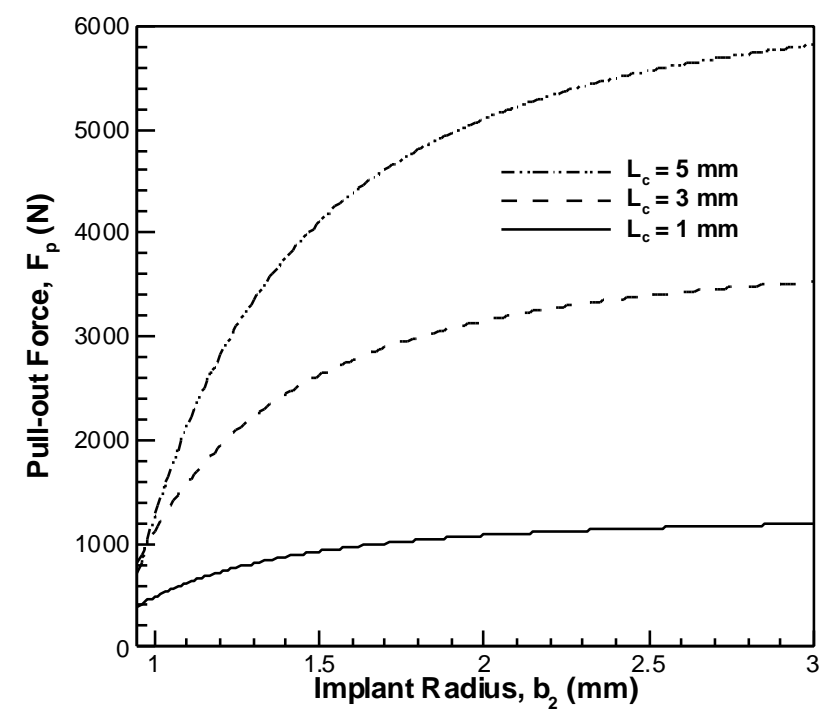

a)

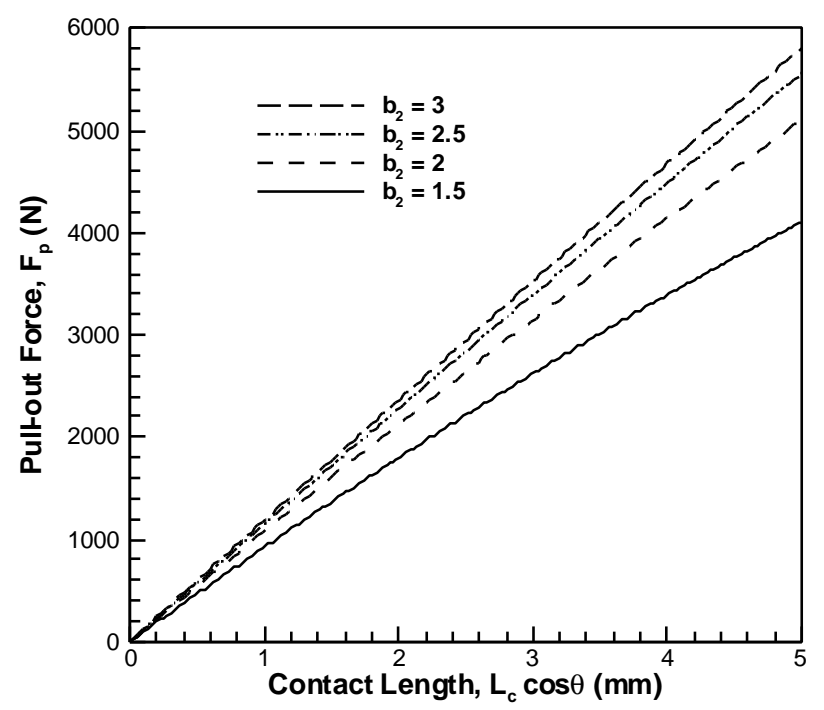

c)

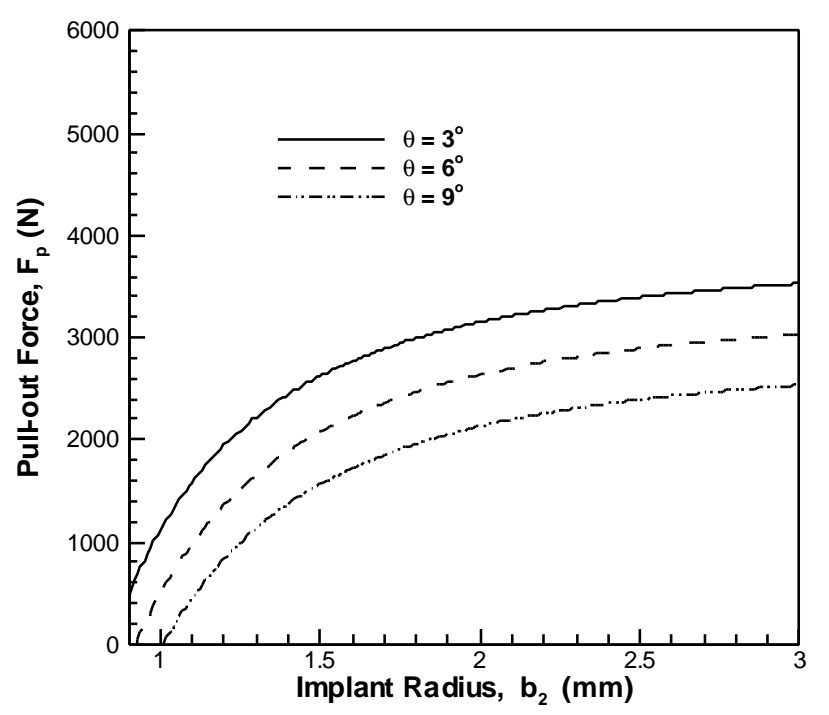

b)

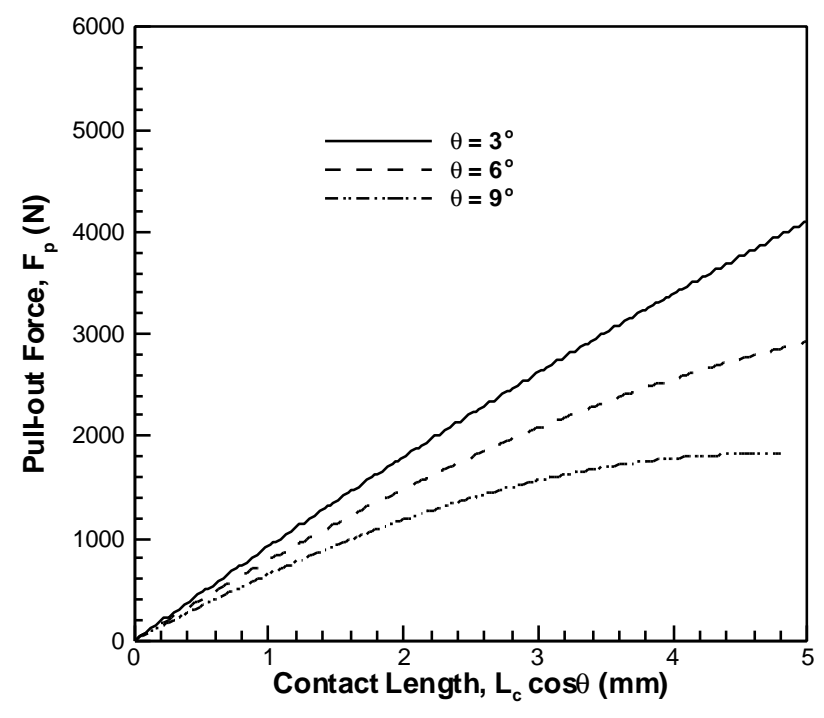

d)

Fig. 4. Variation of the pull-out force $F_{p}$ with implant radius $b_{2}$, contact length $L_{c}$ and taper angle $\theta$ for $r_{i b}=0.7 \mathrm{~mm}, \delta=8 \times 10^{-3}$ and $\mu=0.5$. 


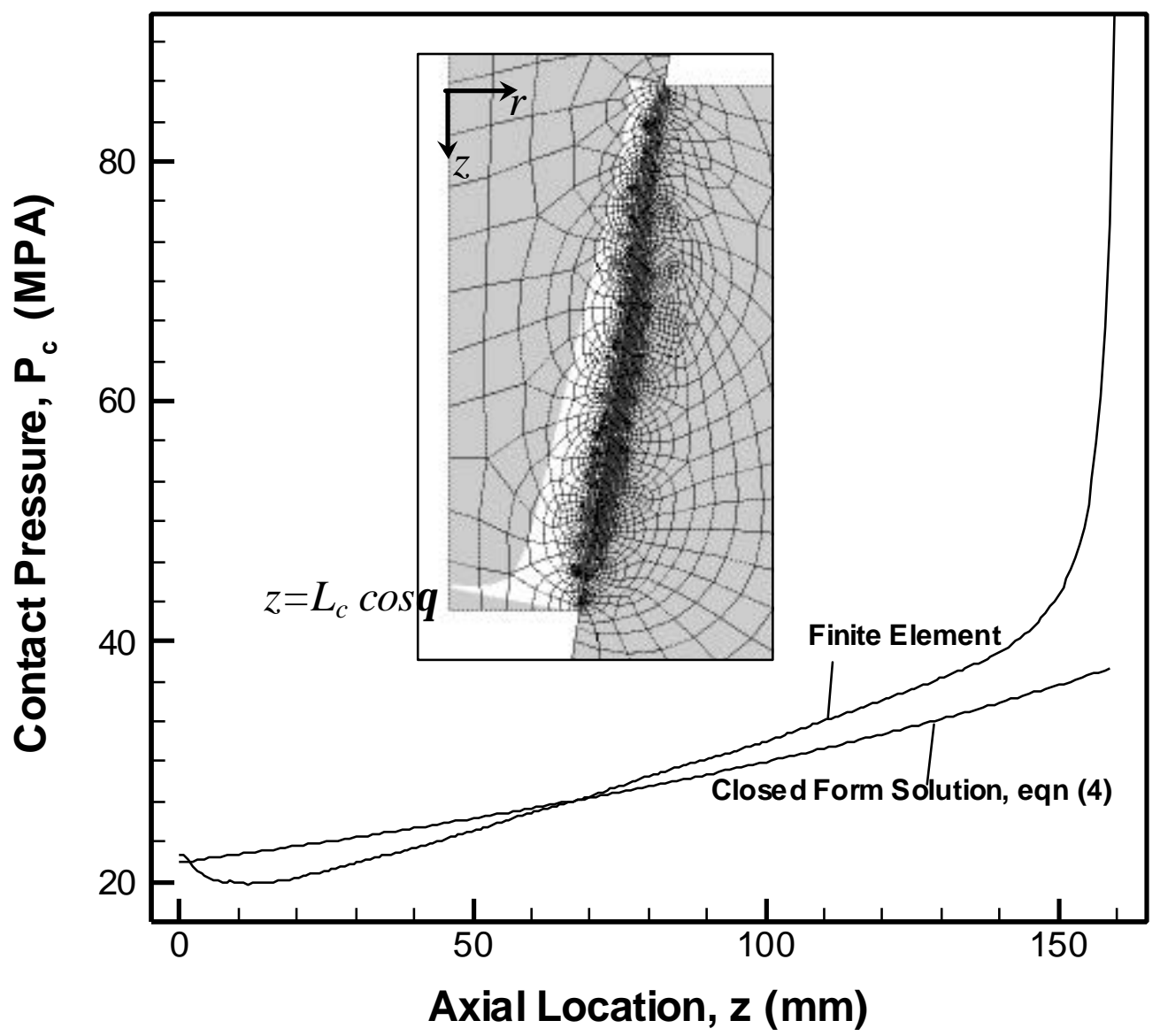

Fig. 5. Comparison of the contact stress distribution predicted by equation (4) and the FEM for $\theta=9^{\circ}, L_{c} / b_{1}=4, b_{2} / b_{1}=3$, and $\delta / b_{1}=16 \times 10^{-3}$. The insert shows the FE mesh used in the solution and the variation of the contact pressure with respect to the abutment-implant interface. 


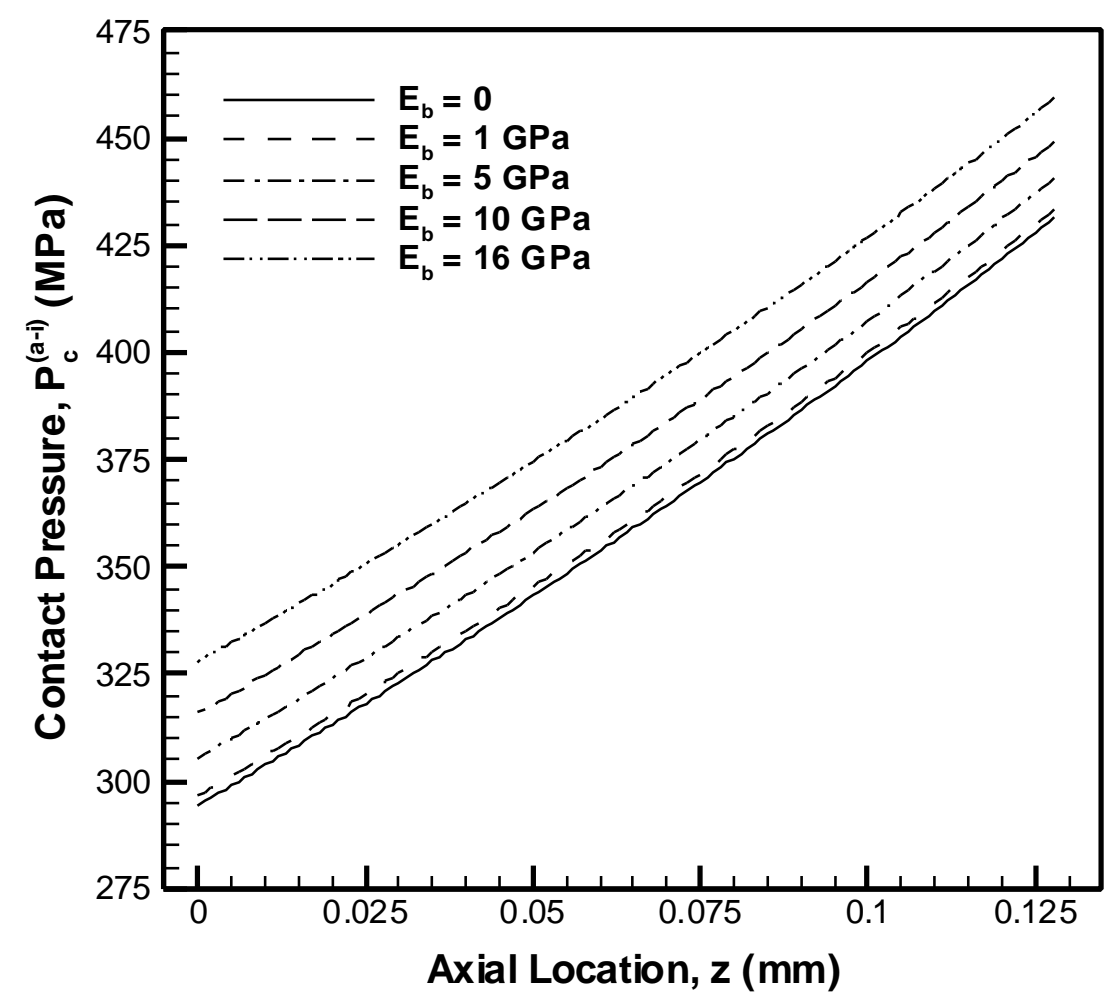

a)

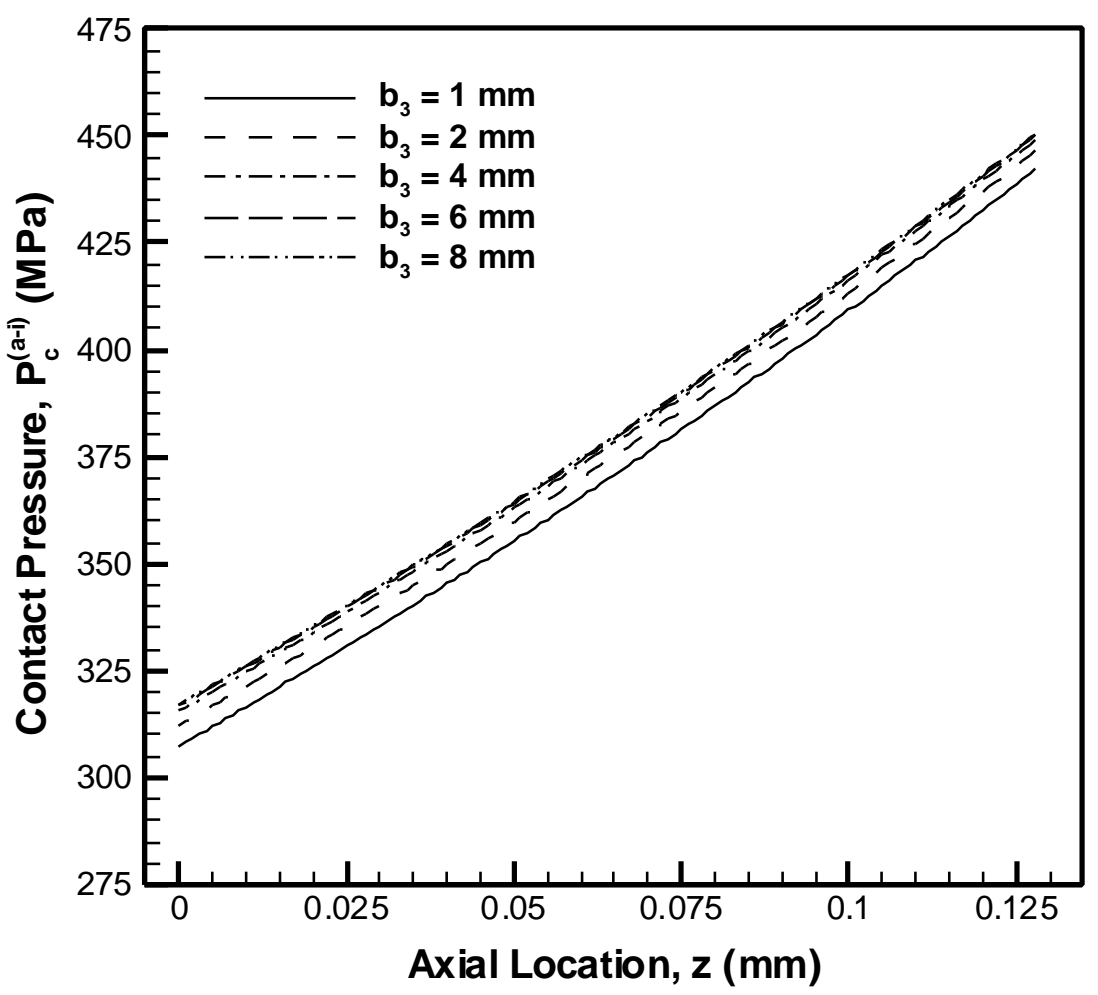

b)

Fig. 6. a) The effect of bone modulus and b) the effect of bone radius surrounding the implant on the contact pressure in the abutment-implant interface $P_{c}^{(a-i)}$, calculated by using equation (4). 


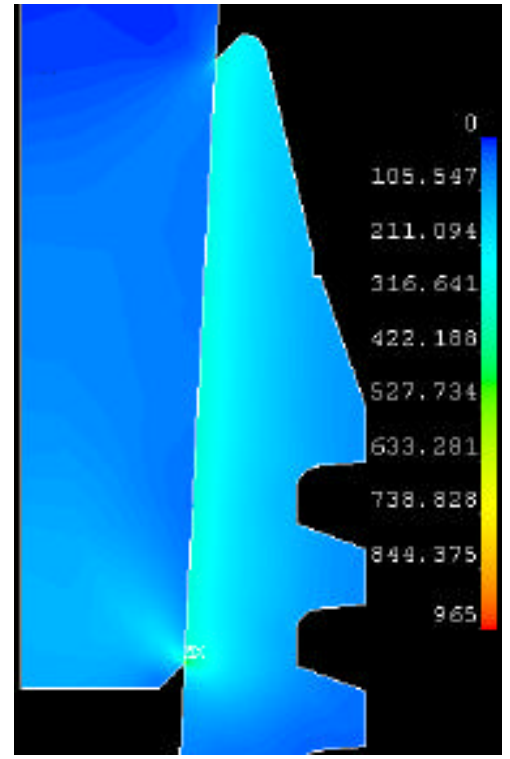

a) $\sigma_{e q}$ at $\Delta z=0.05 \mathrm{~mm}$

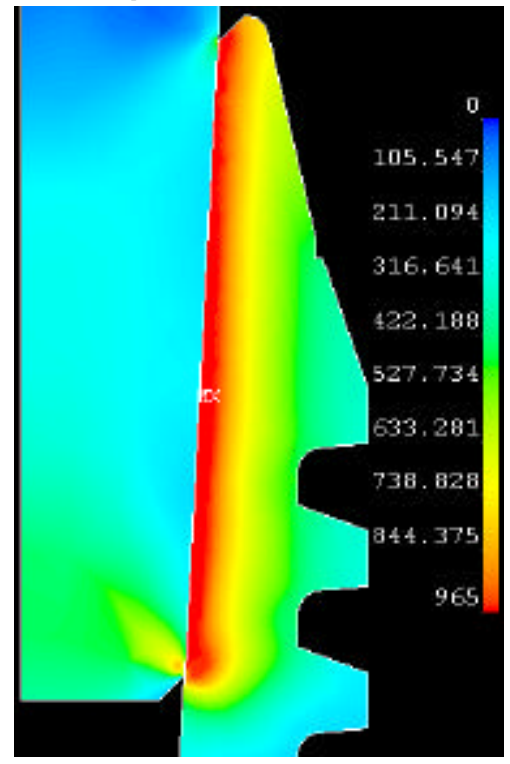

d) $\sigma_{e q}$ at $\Delta z=0.20 \mathrm{~mm}$

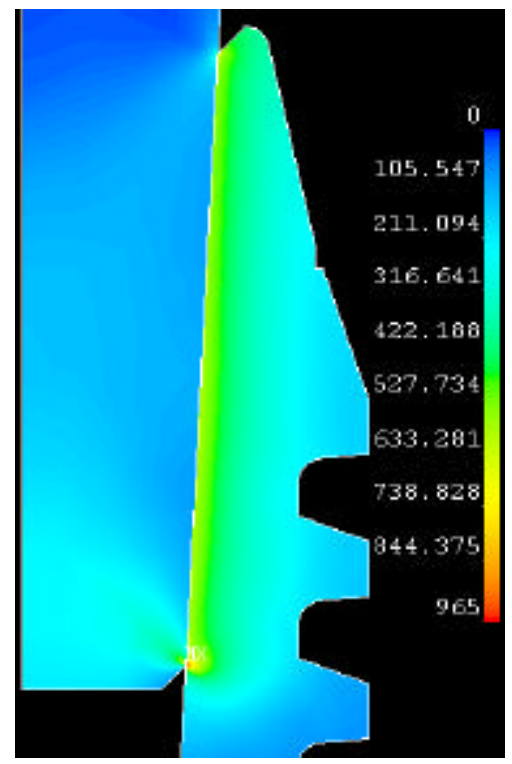

b) $\sigma_{e q}$ at $\Delta z=0.1 \mathrm{~mm}$

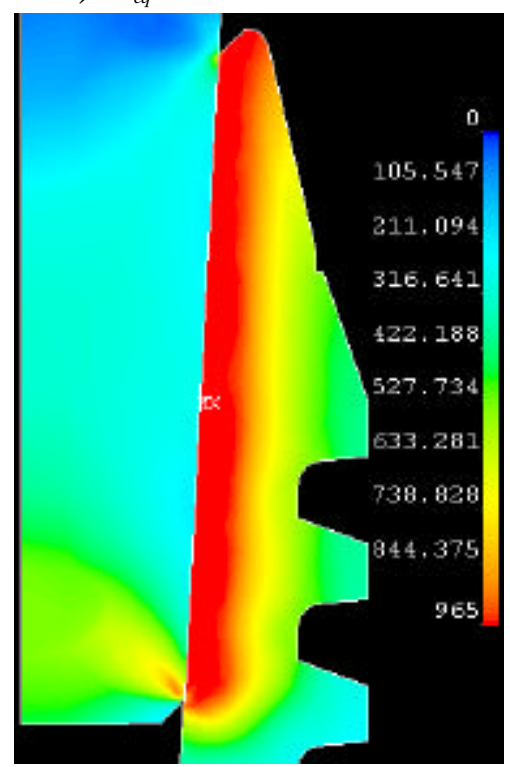

e) $\sigma_{e q}$ at $\Delta z=0.25 \mathrm{~mm}$

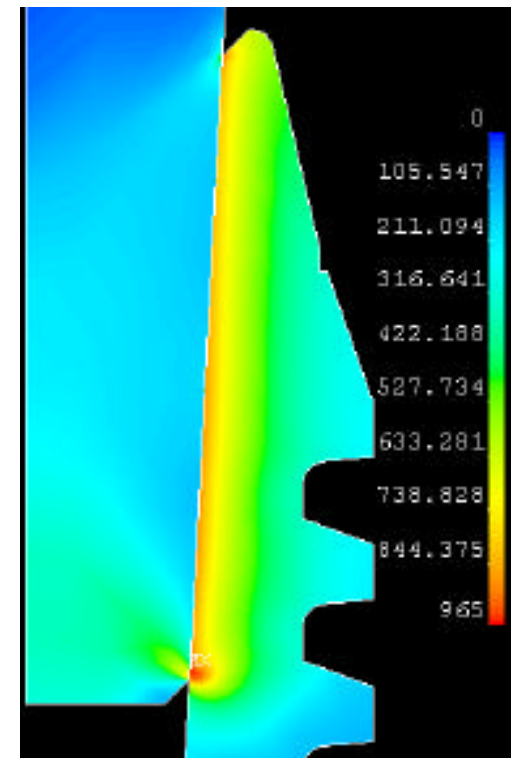

c) $\sigma_{e q}$ at $\Delta z=0.15 \mathrm{~mm}$

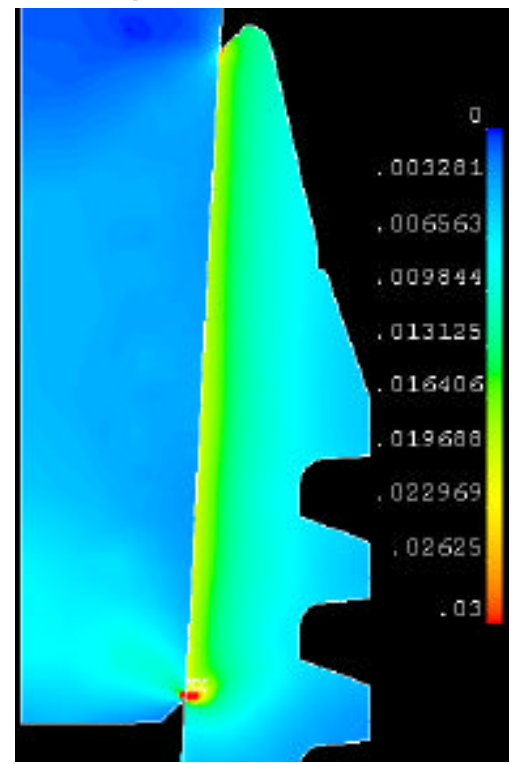

f) $\varepsilon_{e q}$ at $\Delta z=0.25 \mathrm{~mm}$

Fig. 7. The von Mises stress distribution for interference depth values of $\Delta z=0.05-0.25 \mathrm{~mm}$ are given in a)-e). The equivalent von Mises strain for $\Delta z=0.25 \mathrm{~mm}$ is given in f). The yield stress for Ti6Al4V ELI is $\sigma_{Y}=960 \mathrm{MPa}$, and the ultimate strain is $\varepsilon_{\mathrm{U}}=0.08$. Note that the effect of the surrounding bone is included in the analysis but not shown in this figure for clarity of presentation. 


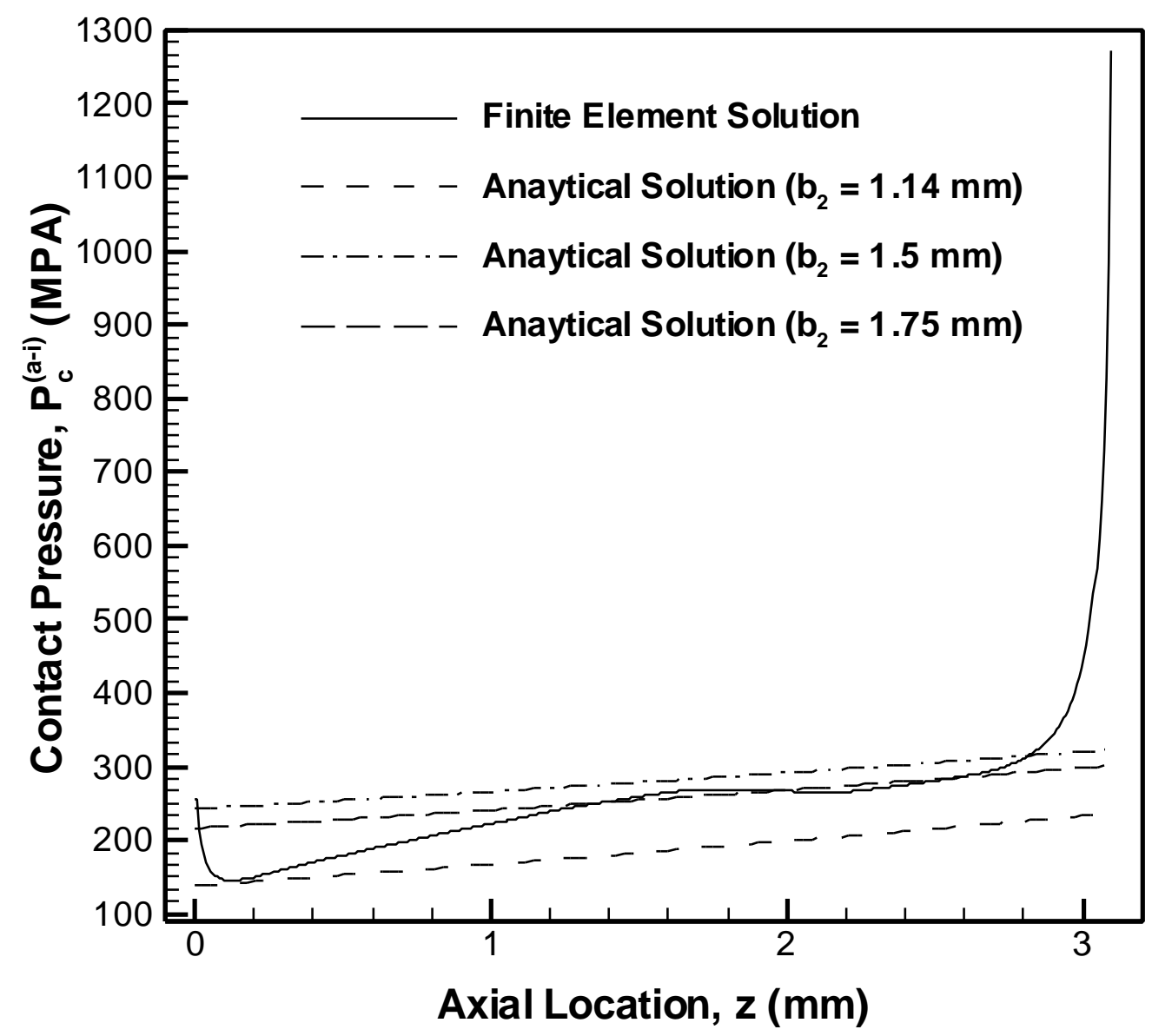

Fig. 8. The contact pressure distribution in the abutment implant interface for the Bicon implant calculated by the FE method for $\Delta z=0.1 \mathrm{~mm}$. The results are compared with the predictions of the closed-form solution given by equation (7) for different implant outer radii. 


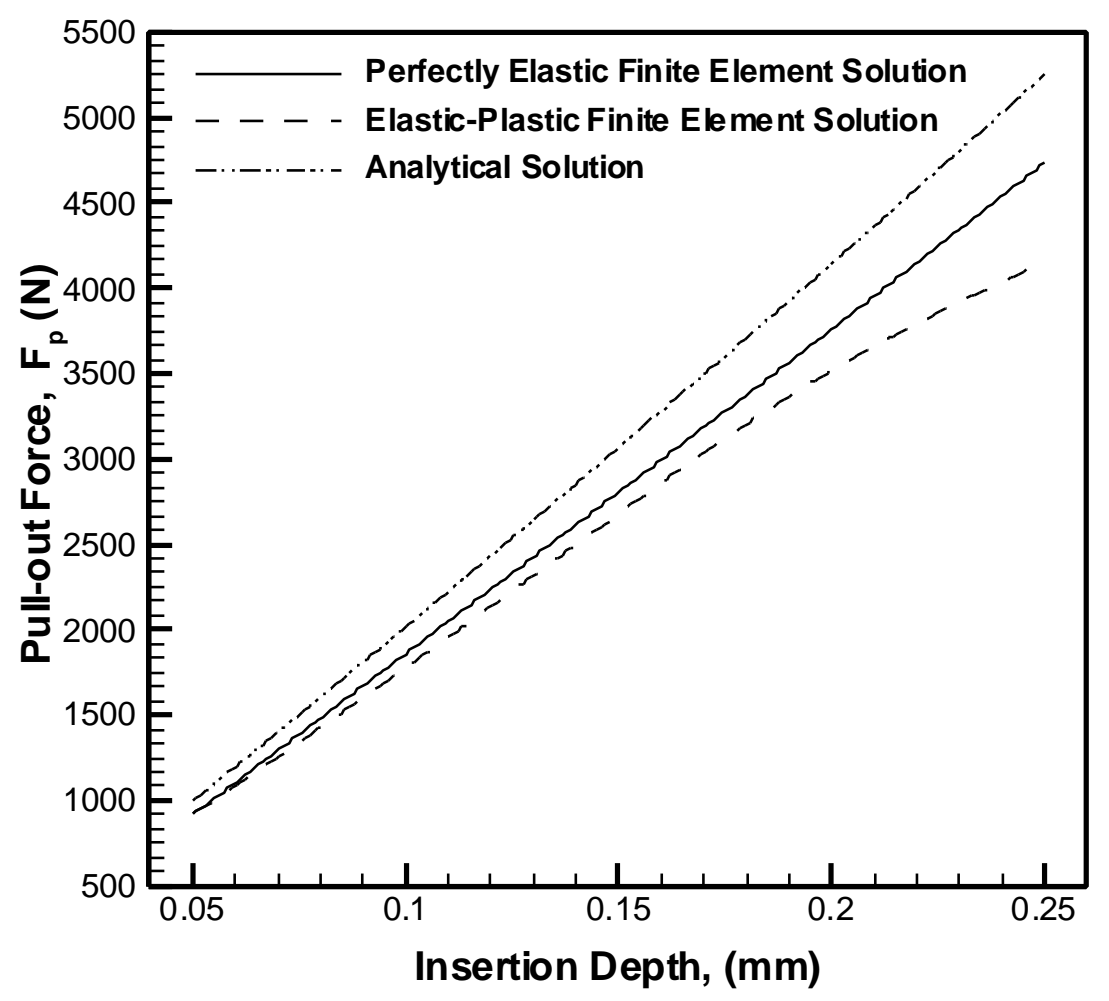

a)

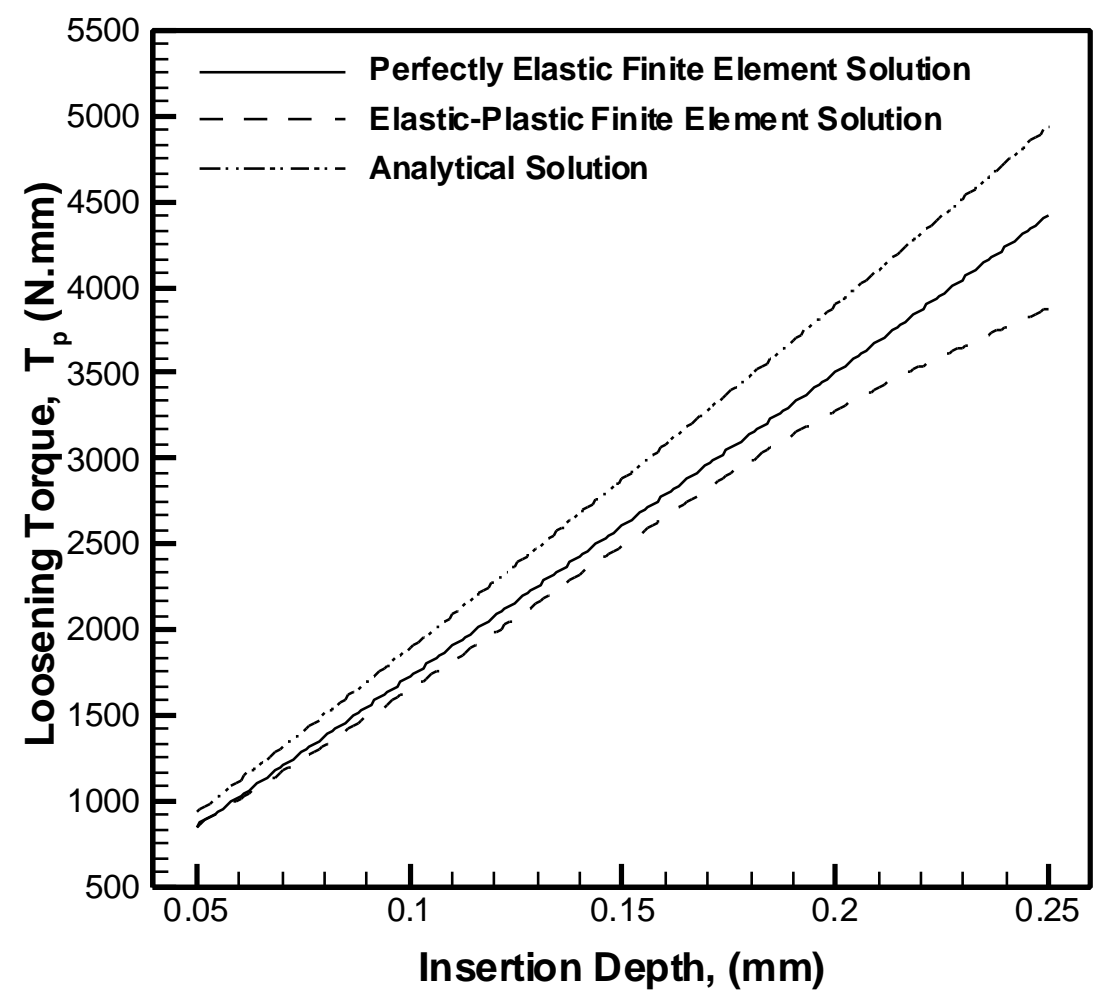

b)

Fig. 9. a) the pull out force and b) the loosening torque for the Bicon implant. The results represent the closed form solution, elastic FEA and elastic-plastic FEA. 